\title{
Responses to Novelty and Vulnerability to Cocaine Addiction: Contribution of a Multi-Symptomatic Animal Model
}

\author{
David Belin ${ }^{1}$ and Véronique Deroche-Gamonet ${ }^{2}$ \\ ${ }^{1}$ INSERM U1084, Laboratoire de Neurosciences Expérimentales et Cliniques, Group Psychobiology of \\ Compulsive Disorders, INSERM Associated European Laboratory Psychobiology of Compulsive Habits, \\ Université de Poitiers, Poitiers-F86022, France \\ ${ }^{2}$ INSERM U862, Neurocentre Magendie, Team Pathophysiology of Addiction, Group Psychobiology of \\ Addiction, Université de Bordeaux, Bordeaux-F33077, France \\ Correspondence: veronique.deroche@inserm.fr
}

Epidemiological studies have revealed striking associations between several distinct behavioral/personality traits and drug addiction, with a large emphasis on the sensation-seeking trait and the associated impulsive dimension of personality. However, in human studies, it is difficult to identify whether personality/behavioral traits actually contribute to increased vulnerability to drug addiction or reflect psychobiological adaptations to chronic drug exposure. Here we show how animal models, including the first multi-symptomatic model of addiction in the rat, have contributed to a better understanding of the relationships between different subdimensions of the sensation-seeking trait and different stages of the development of cocaine addiction, from vulnerability to initiation of cocaine self-administration to the transition to compulsive drug intake. We argue that sensation seeking predicts vulnerability to use cocaine, whereas novelty seeking, akin to high impulsivity, predicts instead vulnerability to shift from controlled to compulsive cocaine use, that is, addiction.

$\mathrm{D}$ rug addiction is a chronic relapsing disorder characterized by loss of control over drug seeking and drug taking, and maintained drug use despite adverse consequences (American Psychiatric Association 2000). Drug addiction, which is also manifested by a powerful craving for the drug, occurs mainly after a prolonged history of drug use and in $20 \%-40 \%$ of users, depending on the drug (Anthony et al. 1994; Nutt et al. 2007). Drug addiction is a complex brain disorder (Leshner 1997) associ- ated with dysfunctions in the motivational (Kalivas and Volkow 2005), emotional (Goldstein et al. 2009), learning (Volkow et al. 2006; Yalachkov et al. 2010), and behavioral control systems (Baler and Volkow 2006; Volkow et al. 2010; Ersche et al. 2011, 2012).

Despite almost five decades of experimental research, both the etiology and the pathophysiology of drug addiction remain largely unknown, resulting in a relative limitation in available effective treatments, especially for stimulant

Editors: R. Christopher Pierce and Paul J. Kenny

Additional Perspectives on Addiction available at www.perspectivesinmedicine.org

Copyright (C) 2012 Cold Spring Harbor Laboratory Press; all rights reserved; doi: 10.1101/cshperspect.a011940

Cite this article as Cold Spring Harb Perspect Med 2012;2:a011940 
addiction (Kreek et al. 2002). This apparent failure consolidates our opinion that most experimental strategies based on a narrow druginduced neuroadaptational view may lead to impasse (Deroche-Gamonet et al. 2004; Belin et al. 2009b; Deroche-Gamonet and Piazza 2010; Belin and Dalley 2012). Indeed, drug addiction is not a mere problem of drug exposure, as it is modeled in most preclinical studies, even based on a so-called gold-standard self-administration procedure. Rather, the predisposition to drug addiction results from the interaction of many different factors, including a vulnerable phenotype or personality, the drug, and the environment.

Keeping that in mind, we think, however, that three main obstacles, relevant for experimental psychopathology in general, could have contributed to hinder our ability to decipher the pathophysiological mechanisms of drug addiction. The main one was related to the unavailability, until recently, of animal models of this complex disorder with heuristic value with regard to its clinical definition. The second obstacle is related to a mechanistic group averagebased experimental approach, which did not consider interindividual differences, a critical feature of the development of addiction, namely, that the drug is not the etiological factor of addiction. All drug users do not face the same individual risk of developing addiction, and individual vulnerabilities should lie at the core of a pertinent experimental approach. Intimately related to the previous ones, the last limitation implies theoretical considerations in that, over the last decades, psychobiological theories of addiction have been developed mostly on the basis of drug-induced behavioral and neurobiological adaptations. However, despite the growing body of evidence that drug use is associated with, and involves, countless psychopharmacological and neurobiological alterations throughout the brain, drug use is far from reflecting drug addiction, thereby impeding the understanding of the effective role, if there is any, of these adaptations in the addiction process.

A decisive step would therefore be to identify the psychobiological substrates specific of those vulnerable users shifting from controlled recreational drug use to addiction, as compared with those who do not shift. The question of vulnerabilities is then probably one of the keys to our ability to understand the physiopathology, or should we say, the physiopathologies of addictions (Badiani et al. 2011), another aspect of this psychiatric disorder that has tended to be forgotten. Indeed, the apparent unified view of drug addiction, at the core of both the clinical definitions and the psychobiological theories of addiction (Koob and Le Moal 2001; Robinson and Berridge 2008), has greatly impacted experimental research, thereby promoting a general wisdom that addiction must be underpinned by alterations of the mesolimbic function because it is a final neurobiological pathway to the effects of all addictive drugs. However, despite a common clinical table and common drug-induced adaptations, distinct physiopathological mechanisms may be involved in the development of addiction, depending not only on drug classes (Badiani et al. 2011), but also on the motivation to initiate drug use (Comeau et al. 2001) and hence individuals' personalities.

Several distinct personality traits, including sensation seeking, anxiety, and impulsivity, have been repeatedly associated with drug addiction (Franques et al. 2000; Bornovalova et al. 2005b; Lejuez et al. 2006, 2008; Verdejo-Garcia et al. 2008; Crews and Boettiger 2009; Ersche et al. 2010, 2011; Fernandez-Serrano et al. 2010). Major differences, however, have been identified in the distribution of these traits and their magnitude in various populations of drug addicts, especially between cocaine, heroin, and alcohol users (Bornovalova et al. 2005a; Lejuez et al. 2008). Drug addicts also exhibit several distinct comorbid psychiatric disorders (Khantzian 1980; Kessler et al. 1996; Skinstad and Swain 2001; Gum and Cheavens 2008) and behavioral or cognitive deficits (Bechara 2005; Ersche et al. 2005, 2008, 2012; Verdejo-Garcia et al. 2006; Salgado et al. 2009; Cunha et al. 2011; Gorodetzky et al. 2011). These differences suggest either that chronic exposure to different drugs alters predominantly different facets of personality or instead that different personality profiles may facilitate the choice of a certain drug and/ or the transition to drug addiction once drug 
use has been initiated. This implies that vulnerability to drug use and vulnerability to addiction would depend on at least partly dissociable phenotypes (Belin et al. 2008; Deroche-Gamonet and Piazza 2010).

These aforementioned distinctions are not easily accessible to experimental testing in humans, not least because epidemiological studies rely on correlational associations, but also because well-controlled longitudinal studies are technically and financially extremely demanding over a period of 20 years. Additionally, the pertinence of epidemiological studies strongly relies on the homogeneity of the studied population. Now, as preclinical research did, epidemiological studies have tended to combine increased drug use and abuse with drug addiction. In addition, the pure addict population, in particular in the context of illicit drugs, is versatile. Therefore, studied populations are often heterogeneous-mixing use, misuse, abuse, and addiction. It is then difficult to identify whether personality/behavioral traits actually contribute to increased vulnerability to drug addiction (Khantzian 1985b) or whether chronic drug exposure triggers the emergence of psychiatric comorbidities or personality/behavioral traits (for discussion, see O'Brien 1997). There is nevertheless emerging evidence from well-controlled sibling studies (Ersche et al. 2012) that family-based investigations may provide better insights into endophenotypes of drug addiction. However, these do not necessarily help us to discern factors of vulnerability to initiate drug use from factors of vulnerability to switch from controlled to compulsive drug use. Thus, both epidemiological and preclinical studies yet have to answer the issue of the existence of different vulnerable factors involved in the different phases of the addiction process-namely, use, abuse, and addiction.

Therefore, the role of animal models is pivotal in the understanding of the dynamics of the etiological process because they allow us to dissociate the preexisting phenotypes from druginduced adaptations for each stage of the drug exposure history. Altogether, to date, animal models provide a valuable means to investigate the different stages of the drug addiction cycle, including especially the initiation of drug taking; the maintenance phase, which is often accompanied by bouts of drug bingeing and escalation; and, finally, the switch to compulsive drug intake, defined operationally by an increased motivation to take the drug, an inability to inhibit drug seeking, and continued drug use despite negative or adverse consequences. In this context, the most recent preparation is a multi-symptomatic model of addiction that uniquely allows studying processes underlying interindividual vulnerability to shift from controlled to compulsive drug use (Deroche-Gamonet et al. 2004; Belin et al. 2008, 2009a, 2011a,b; Kasanetz et al. 2010; Belin and Dalley 2012).

In this article, we focus on cocaine addiction for three main reasons. First, models of addiction-in particular, the multi-symptomatic, so-called, 3-criteria model-have been developed for cocaine. Although researchers are currently involved in producing models of compulsive drug use for drugs of other classes, none are currently available and as validated as the ones for cocaine. Second, there is an important increase in cocaine consumption all over the world and in particular in young Europeans (WHO 2004; European Monitoring Centre for Drugs and Drug Addiction 2009; Wiessing et al. 2009). And last, but not least, cocaine addiction is one of the poorest addictions in terms of available therapies, including substitutive ones.

With regard to individual vulnerability, we focus on the contribution of preclinical studies to our understanding of the possible role of behavioral/personality traits in the addiction process with a large emphasis on responses to novelty and risk. The case of novelty responses is one of the best documented and exemplary in several aspects.

\section{VULNERABILITY TO DRUG ADDICTION: CONTRIBUTING FACTORS}

There is a general wisdom that vulnerability to psychopathology results from complex interactions over prolonged periods of time. If addiction responds to this general agreement, still little is known regarding the factors involved in the vulnerability to develop this psychiatric 
disorder. An old dyadic model (Ausubel 1961) combined predisposing factors, that is, hereditary or acquired susceptibility, and precipitating factors, namely, drug and environment (drug availability, community or societal tolerance, peer and family domains, etc.). This model had the interest of clearly evoking vulnerability through predisposition and introduced a dual, almost functional, dissociation into individualrelated factors and external factors that placed the individual at the core of vulnerability. A triadic model has since then been consensually established. Whatever the view-psychodynamic, psychosocial, psychiatric, or neuroadaptivevulnerability to drug addiction is suggested to result from the interaction between a vulnerable phenotype or personality (being the interaction between genetics and history), the drug, and the environment. Genetic, especially twin, studies have revealed that genetic factors may account for $40 \%$ of the vulnerability to drug addiction (for review, see Koob and Moal 2005), thereby leaving a pivotal role to history, hence personality, and the iatrogenic effects of the substance.

\section{The Vulnerable Phenotype(s) and Drug(s)}

Drug addiction is associated with numerous distinct behavioral/personality traits, psychiatric comorbidities, and behavioral and cognitive deficits. It is largely unknown whether these behavioral deficits, personality traits, and psychiatric disorders contribute to addiction or are simple consequences of drug use. It can also be questioned whether they are vulnerability markers either for distinct phases of the addiction process or for addiction to different classes of drugs. Finally, they could also be vulnerability markers for distinct etiological/neurobiological mechanisms of the same addictive process.

Besides their disinterest for alternative sources of reinforcement and their focus on the drug, drug addicts can indeed be characterized by several behavioral and cognitive deficits including impaired inhibitory control (Kirby and Petry 2004; Mitchell et al. 2005; Baler and Volkow 2006; Dom et al. 2006; Verdejo-Garcia et al. 2007b, 2008), decision making (Grant et al. 2000; Monterosso et al. 2001; Bechara and Damasio 2002; Hester and Garavan 2004; Bechara 2005; Cunha et al. 2011), and insight (Goldstein et al. 2009; Verdejo-Garcia and Bechara 2009; Naqvi and Bechara 2010).

Several distinct personality traits, including sensation seeking, anxiety, and impulsivity, are also associated with addiction (Gossop 1978; Labouvie and McGee 1986; Zuckerman 1986; Greene et al. 1993; Clapper et al. 1994; Schinka et al. 1994; Ball et al. 1998; Franques et al. 2000; Conway et al. 2002; Franques 2003; Gerra et al. 2008; Terracciano et al. 2008). Not only are these associations highly heterogeneous within the same drug addict population, with one subset showing high anxiety and others showing high impulsive/sensation-seeking traits (Gunnarsdottir et al. 2000), but they also depend greatly on the substance used. Indeed, although both cocaine and heroin addicts show increased levels of sensation seeking (Allcock and Grace 1988; Gerra et al. 2004; Maremmani et al. 2009), anxiety (Lejuez et al. 2008), and impulsivity (Madden et al. 1997; Kirby et al. 1999; Coffey et al. 2003; Bornovalova et al. 2005a; Clark et al. 2006; Verdejo-Garcia et al. 2007b, 2008), heroin addicts show greater anxiety sensitivity than cocaine addicts do (Lejuez et al. 2006), whereas the latter display higher impulsivity (Bornovalova et al. 2005a; Lejuez et al. 2005; Verdejo-Garcia et al. 2007b). Additionally, some personality traits or psychiatric disorders are more specifically associated with vulnerability to use (Zuckerman 1986; Franques et al. 2000; Sher et al. 2000; Terracciano et al. 2008) or to addiction (Swendsen and Le Moal 2011), thereby rendering even more complex the relationships between personality traits and the etiology of drug addictions.

According to the psychodynamic view of addiction, it is therefore possible that heroin and cocaine users may self-medicate different personality characteristics or affective states (Khantzian et al. 1974; Khantzian 1989, 1991, 1997; Teichman et al. 1989), with impulsivity being preferentially self-medicated by cocaine use (Dalley et al. 2005, 2011). Anyway, the relative contribution of a behavioral trait to the choice of a drug does not necessarily predict its implication in the transition to compulsive drug use. 


\section{The Environment}

There is compelling evidence that life experiences and environments highly influence the effects of drugs of abuse and play a critical role in the transition from controlled to compulsive drug use (Swadi 1999; Batts et al. 2005). However, one must be cautious, because the term environment is often used confusingly. For instance, drug addiction seems to be more frequent in people both living in degraded areas and undergoing difficult experiences during their childhood. In the former, environmental conditions can refer to drug availability, peer pressure, societal tolerance, and/or negative family relationships. Accordingly, positive family relationships, friendships, involvement, and attachment appear somehow to protect against the development of drug addiction (Jessor and Jessor 1980; Jessor et al. 1980). In the latter, environmental influences are exercised at critical developmental phases (perinatal, adolescence) and may alter one's personality and psychobiological construction so that he becomes more vulnerable to use or abuse drugs (Khantzian 1986). It remains to be proven that the two types of environmental conditions play the same kind of influence. The first one may be more a permissive/precipitating factor than an actual factor contributing to establish sustained drug use (Piazza and Le Moal 1996; Somaini et al. 2011) or promote transition to compulsive drug use, as could be the second one.

\section{Vulnerability to Addiction: The Result of Complex Interactions}

Although we are gaining increasing insights into the nature of the factors contributing to addiction, our knowledge regarding the functional nature of their contribution remains limited. Why then? Interactions between factors contributing to the vulnerability to addiction are considered to be complex. However, complexity of addiction itself has probably been underestimated in two major domains:

1. The same clinical diagnosis does not necessary imply the same physiopathology and etiology. A unitary view governs all current clinical definitions and theories of addiction. Although addicts share a common clinical definition, underlying mechanisms could be of different kinds. The clinical definitions propose seven criteria, and a positive diagnosis is given when the patient shows three of them over a period of 12 months preceding the interview. Therefore, the same diagnosis, that is, addiction, does not necessarily depend on the same clinical table between two patients. These interindividual differences reflected in differential combination of symptoms within the same diagnosis should be better considered in clinical practice and experimental research. This could even be best evidenced when considering distinct classes of drugs, although it remains questionable whether drug specificities are preexisting differences or drug-induced ones.

2. Addiction is a multistep pathology (Kreek et al. 2002; Belin et al. 2011b). We know, from its natural history, that the pathology progresses from use to addiction through regular use or abuse. Attempts to quit, that is, withdrawal periods, are unsuccessful in the great majority of addicts and define the relapsing nature of addiction. Different kinds of factors and mechanisms of vulnerability could be involved in the transition from one stage of the pathology to the other, but also within the same stage. This is particularly easy to conceive for relapse. Different relapsing factors have been identified, namely, stress, drug-associated conditioned stimuli, and small amounts of drug (Childress et al. 1988; Goeders 2003). Preclinical models of relapse, that is, reinstatement models, allowed evidencing distinct neurobiological mechanisms involved for the three types of factors, providing numerous sources for mechanisms of vulnerability (Le and Shaham 2002; Shalev et al. 2002).

Considering this, our current view of vulnerability could be distorted. According to the literature, genetic (hereditary) factors may contribute up to $40 \%$ to the development of drug addiction (Kreek et al. 2002). This estimation gives genetic factors a rather limited 
contribution to the vulnerability to drug addiction, but does it necessarily imply that the drug and the environment are keys for vulnerability? The respective weight of genetic and environmental factors in vulnerability could finally be a function of the phase of the addictive process. In addition, the genetic contribution to vulnerability could be an indirect one. It could define an increased vulnerability to detrimental environmental factors as suggested by the growing literature on the role of gene-environment interactions (Caspi and Moffit 2006; van der Veen et al. 2007, 2008).

In summary, a lot is known regarding factors associated with addiction. Little is known, however, regarding the factors and mechanisms involved specifically in the vulnerability to develop drug addiction. Data strongly suggest that vulnerability to addiction is specific and distinct from vulnerabilities to use and abuse. In addition, vulnerability to addiction could be plural because several subpopulations may exist within drug addicts.

\section{ANIMAL MODELS OF DRUG VULNERABILITY}

In the context of vulnerability, animal models are determinant because they allow, within well-controlled longitudinal studies, dissociating preexisting phenotypes from drug-induced adaptations (Deroche-Gamonet et al. 2004; Belin et al. 2008, 2011a; Kasanetz et al. 2010; Belin and Dalley 2012). This has proven very useful for a better understanding of endophenotypes of individual vulnerability to drug addiction, such as decreased D2 dopamine receptor levels in the ventral striatum (Dalley et al. 2007) and their associated increased impulsivity (Belin et al. 2008) or novelty preference (Belin et al. 2011a), and increased response to cocaine-induced seeking or a fast early pattern of drug use (Belin et al. 2009a).

Preclinical models have major limitations that must be kept in mind (Geyer et al. 1995). They surely do not allow capturing all aspects of the pathology, nor can they deal with the complexity of the pathology as a whole, including the complex social, and often personal, reasons leading people to use and abuse drugs, and the environmental factors such as peer pressure, societal tolerance, taboos, and social environment. However, quite similar limitations have been encountered in clinical studies so far, and, as noted above, it remains to be proven that these factors do not exclusively play a permissive role in revealing vulnerability to drug use.

However, with the increasing evidence suggesting that drug addiction results from gradual adaptation processes in the brains of vulnerable subjects in response to chronic drug exposure (Belin et al. 2009b, 2011b; Belin and Everitt 2010; Deroche-Gamonet and Piazza 2010; Kasanetz et al. 2010), animal models present a unique tool to discriminate both psycho- and neurobiological mechanisms involved in individual vulnerability to acquire drug use from those specifically involved in drug-induced neuroadaptations responsible for the transition to drug addiction. Thus, preclinical models provide a rigorous mean to control drug exposure precisely as well as assess behavioral and cognitive performance before drug administration. They also enable controlled neural manipulations to be made (Belin and Everitt 2008) and thus establish the causal influences of putative neural loci and, in turn, the cellular and molecular substrates of drug addiction (Kasanetz et al. 2010).

A major challenge of addiction research in recent years has been to develop models for studying compulsive drug use (Deroche-Gamonet et al. 2004; Vanderschuren and Everitt 2004; Pelloux et al. 2007) with great heuristic value with regard to the clinical definition of the pathology, instead of a mere drug self-administration model, which has initially been developed in rats in 1962 by the seminal work of Weeks (1962). Notably, this has yielded to the development of the first multi-symptomatic model of addiction based on the DSM-IV criteria (Deroche-Gamonet et al. 2004). This model, based on interindividual differences and protracted exposure to cocaine self-administration provides a unique tool to identify $15 \%-20 \%$ of drug-exposed rats that shift from controlled to compulsive self-administration despite equal cocaine intake. 
Novelty and Addiction

Comparing addict-like and non-addict-like rats allows disentangling common drug-induced adaptations from those specifically associated with the addiction phenotype (DerocheGamonet et al. 2004; Belin et al. 2008, 2009a, 2011a; Kasanetz et al. 2010). In addition, this model allows for a direct understanding of the psychobiological mechanisms underlying the pathological shift from controlled use to addiction (Belin et al. 2009a; Kasanetz et al. 2010). Finally, it uniquely addresses a major aspect of the pathology, that is, individual differences, the key to apprehend vulnerability.

\section{Modeling Vulnerability to Drug Use in Rodents}

Piazza et al. (1989) were among the first to consider interindividual differences in drug responses, thereby introducing the concept of "vulnerability" in preclinical research on addiction. They showed that vulnerability to drug use can be predicted by a behavioral trait measured in naive animals, namely, locomotor reactivity to a novel, inescapable environment, proposed as a model of sensation seeking (Dellu et al. 1996). Rats are placed for $2 \mathrm{~h}$ in a new environment, and their horizontal activity is monitored. Based on interindividual differences in locomotor response, animals are either selected as high responders (HRs) or low responders (LRs) according to a median division (Piazza et al. 1989). HR rats show a greater propensity to acquire psychostimulant self-administration (Piazza et al. 1989). They more readily self-administer low doses of psychostimulants than LR rats do (Piazza et al. 1989; for review, see Piazza and Le Moal 1996; Belin et al. 2008) and show higher cocaine intake whatever the dose tested (Piazza et al. 2000). HR rats are more vulnerable than LR rats to the induction of behavioral sensitization (Hooks et al. 1992) produced by repeated injections of amphetamine. The hypothesis that cocaine has an increased efficacy in HR rats is supported by the greater propensity for drug-induced neural plasticity (Hooks et al. 1991a,b) and increased stress-evoked dopamine release in the nucleus accumbens (Piazza et al. 1991) in these animals.

\section{Modeling Vulnerability to Addiction in Rodents}

\section{The Multi-Symptomatic Model of Addiction}

Three diagnostic criteria-namely, (1) an inability to refrain from drug seeking, (2) high motivation for the drug, and (3) maintained drug use despite negative consequences-have been operationalized in rats by (i) drug seeking during periods when the drug is not available and signaled as so, (ii) break points during progressive ratio schedules of reinforcement (Fig. 1), and (iii) persistence of self-administration despite punishment by contingent electric footshocks (Fig. 2). These criteria are used to evaluate the severity of drug use after prolonged exposure to the drug according to a daily selfadministration protocol. The daily self-administration session is composed of three drug components (40 min each) separated by $15-\mathrm{min}$ drug-free periods. "Drug" periods are signaled by the house light, whereas the "no-drug" periods are signaled by either illumination of the entire self-administration box with extinction of the house light (Deroche-Gamonet et al. 2004; Belin et al. 2009a, 2011a; Kasanetz et al. 2010) or extinction of the house light, depending on the study (Belin et al. 2008). During the "no-drug" periods, instrumental responses are without scheduled consequences. During the "drug" periods, the drug is available according to an FR5-40secTO schedule of reinforcement. A white cue light located above the active hole or lever is associated with drug delivery and serves as a conditioned stimulus (for details on the experimental procedure, see Deroche-Gamonet et al. 2004; Belin et al. 2008, 2009a, 2011a).

\section{The "Diagnosis"}

Our approach consists of ranking rats for their scores for each of the three addiction-like tests. If a rat's score is included in the $30 \%-40 \%$ highest percentile of the distribution, this rat is considered positive for that addiction-like criterion and is given an arbitrary criterion score of 1 (Fig. 3). Then the arbitrary criteria scores for each of the three addiction-like criteria are added, and consequently four distinct groups 


\section{$\$_{\mathrm{CSH}}^{\infty}$ Cold Spring Harbor Perspectives in Medicine

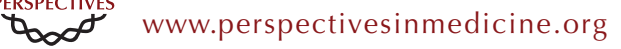

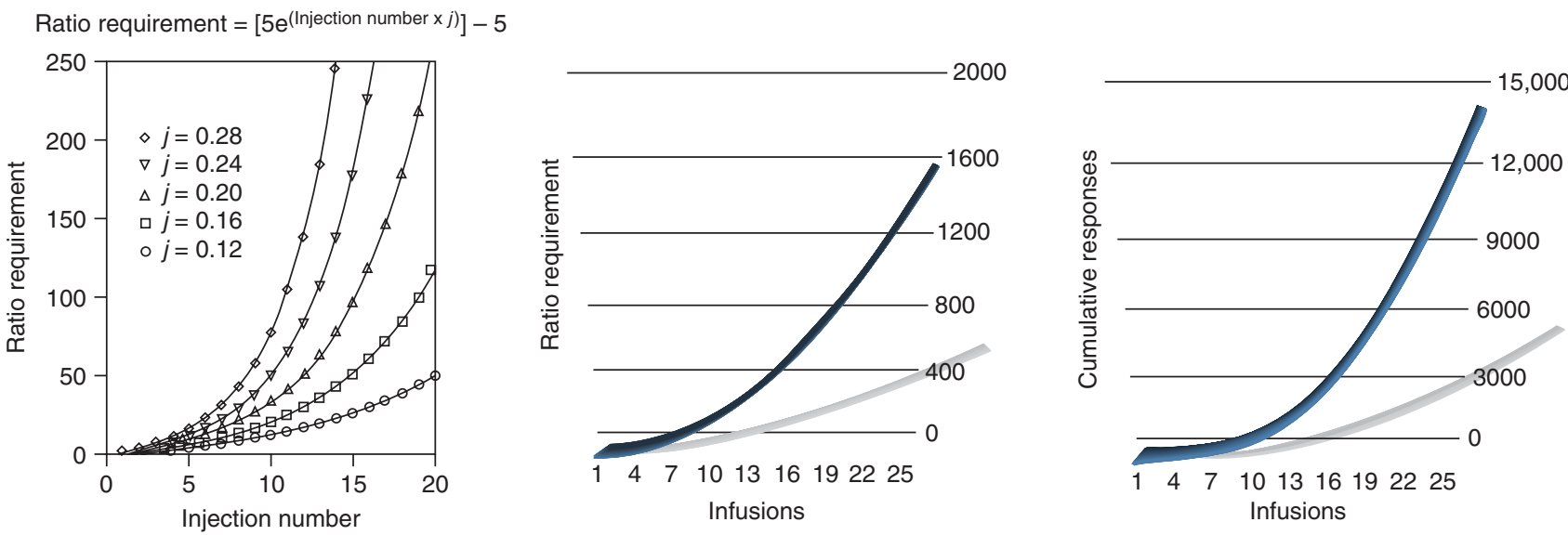

Figure 1. Progressive ratio schedule of reinforcement. The progressive ratio schedule of reinforcement used in the present model is more behaviorally demanding than the ones classically used (Richardson and Roberts 1996). (Left panel) Various PR series, with $j$ $=0.2$ being the most extensively used one. As illustrated in the middle (ratio requirement) and right (cumulative responses) panels, the progressive ratio schedule of cocaine reinforcement used in the present model is far more behaviorally demanding than the classically used ones. Thus, whereas the 15th infusion requires 225 lever presses in the $j=0.2$ procedure, it requires 515 lever presses for 2870 cumulative responses in the current model. 


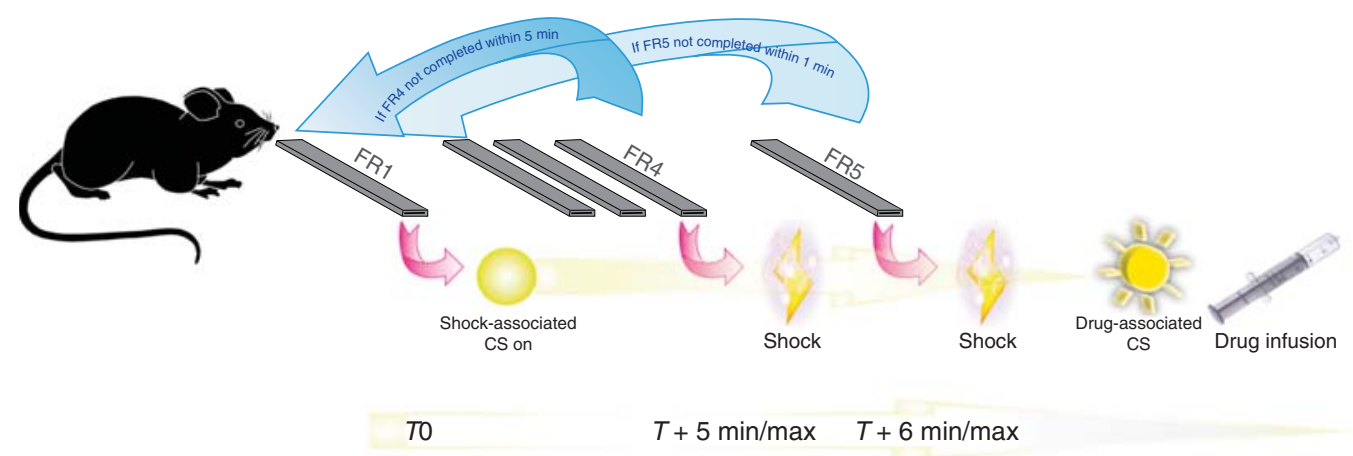

Figure 2. Punishment schedule. The schedule is the following: As for basal training sessions, an animal earns a cocaine infusion after completion of an FR5. However, the first instrumental response leads to the illumination of a green cue light signaling the presence of the shock. When an FR4 is completed within 5 min, rats receive an electric shock $(0.4 \mathrm{~mA}, 2 \mathrm{sec})$; if not, the sequence is reinitialized. When FR5 is reached within a minute, rats receive an electric shock $(0.4 \mathrm{~mA}, 2 \mathrm{sec})$ and then a cocaine infusion paired with its conditioned stimulus (CS). Then the shock-paired stimulus turns off. The schedule can reinitiate at the end of the time-out period, that is, 40 sec after the infusion. If, within a minute, animals do not complete the fifth lever press of the FR5 sequence, leading to the shock-cocaine presentation, the shock-associated stimulus turns off and the sequence is reinitiated.

are identified according to the number of positive scores: 0-criteria (0crit), 1-criterion (1crit), 2 -criteria (2crit), and 3-criteria (3crit) rats.

An analysis of the distributions of each of the three addiction-like behaviors (Belin et al. 2011a) revealed that the distribution of the motivation for the drug and the persistence of drug seeking were best fitted by a lognormal regression, whereas the distribution of resistance to punishment was bimodal, composed of a first lognormal distribution and a second normal subdistribution (Belin et al. 2011a). The bimodal quality of the distributions depends on the challenging nature of the test. In this context, it is pertinent that only resistance to punishment might distribute bimodally. This bimodal distribution can, however, be influenced by additional factors such as the time at which the test is performed and whether rats have experienced the test after early training or not. The later the test is conducted after session 50 , the better do the two subpopulations diverge. Early experience with the test produces the same effect. This is confirmed by the already published progression in the three scores from early to late training in the two groups (Deroche-Gamonet et al. 2004). At any rate, this bimodal distribution provides us with an objec- tive criterion to determine a threshold in the population in order to carry out this dichotomous, categorical strategy to identify animals that show addiction-like behavior, that is, the $30 \%-40 \%$ highest part of the population. And importantly, as discussed above (DerocheGamonet et al. 2004; Belin et al. 2009a), the scores in the three addiction-like behaviors are linearly related to the number of addiction-like criteria met (Fig. 4A-C). This result, obtained with the dimensional approach (scores for each criterion), strongly supports the categorical approach (number of positive criteria). These data support the view that addiction represents a pathologic continuum, from controlled to compulsive use, that is reached by a limited number of drug users. 1 crit and 2 crit rats either represent specific stable cocaine "use-related troubles" or intermediate steps toward addiction.

Developed in 1980 (McLellan et al. 1980), the Addiction Severity Index (ASI) has been extensively used to determine the magnitude of functional and social impairments in drug addicts, thereby providing addiction with a dimensional rating that helps better define addiction severity than the categorical approach inherent to the diagnostic strategy (McLellan et al. 
D. Belin and V. Deroche-Gamonet

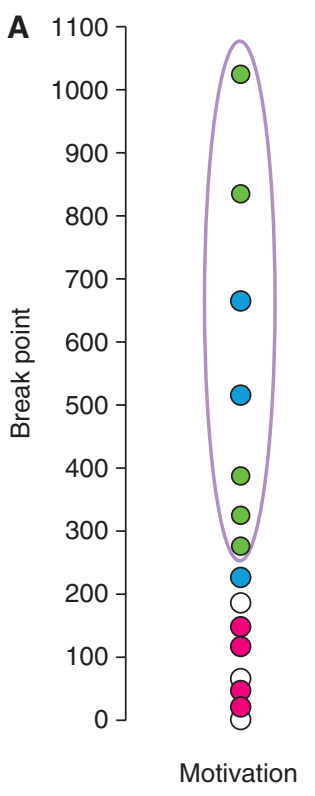

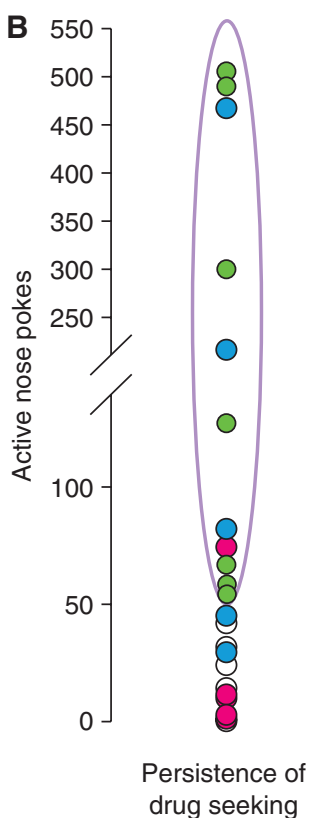

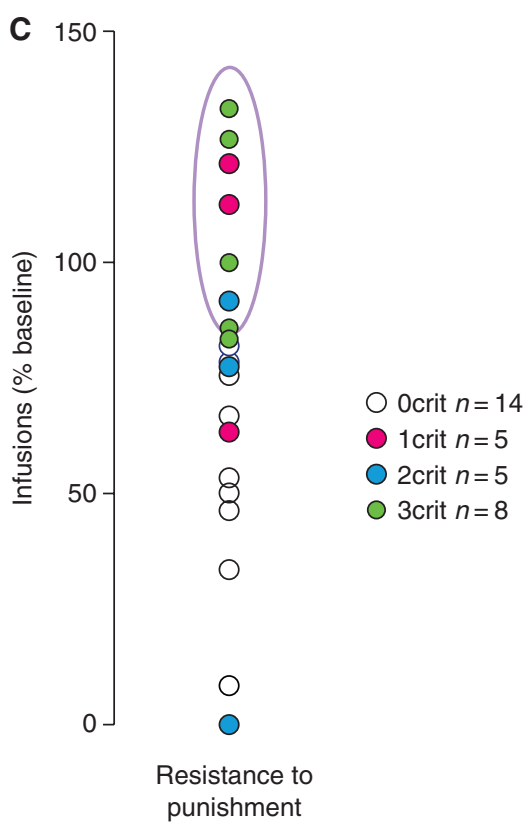

Figure 3. Selection strategy of 3 crit and 0 crit rats. A dichotomous approach to the diagnosis of addiction-like behavior can be implemented in preclinical models of addiction on the understanding that some, but not all, animals chronically exposed to drug self-administration eventually develop one or more behavioral features resembling a clinical criterion for drug addiction as defined in the DSM-IV. Thus, we have operationally defined three addiction-like criteria, namely, $(A)$ increased motivation to take the drug, $(B)$ an inability to refrain from drug seeking, and $(C)$ maintained drug use despite aversive consequences. For each of the three addiction-like criteria, animals are ranked according to their score. If a rat's score is included in the $30 \%-40 \%$ highest percentile of the distribution, this rat is considered positive for that addiction-like criterion and is given an arbitrary criterion score of 1 . Then the arbitrary criteria scores for each of the three addiction-like criteria are added, and consequently four distinct groups are identified according to the number of positive scores: 0criteria, 1-criterion, 2-criteria, and 3-criteria rats. (Data analyzed from Deroche-Gamonet et al. 2004.)

1992; Cacciola et al. 1997; Kampman et al. 1998; Rikoon et al. 2006; Alterman et al. 2007). A dimensional score of addiction-like behavior is fundamental for the study of predictive factors of drug addiction that is mainly based on dimensional, such as correlation, analyses. An addiction score (AS) has been developed as the algebraic sum of the normalized values $(z-$ scores) of each of the addiction-like behaviors (Fig. 4D) (see Belin et al. 2009a). It is highly representative of each of the three criteria, thereby providing one variable representing the addiction-like phenotype. Importantly, the addiction score is an objective scale because it is not dependent on the criteria selection threshold, for example, the $25 \%-40 \%$ highest part of the population.

\section{Validity of the Model}

Our model is based on the comparison of 3criteria (3crit) and 0-criteria (0crit) rats. 3 crit rats show high scores for each of the three addiction-like criteria and are therefore considered "addicted-like," whereas 0crit rats are considered resistant to addiction. 3crit rats represent $\sim 20 \%$ of the population exposed to cocaine (Fig. 4E), an incidence observed in several independent studies with Lister-Hooded or Sprague-Dawley rats as well as either nose poke or lever press as instrumental response (Deroche-Gamonet et al. 2004; Belin et al. 2008, 2009a, 2011a; Kasanetz et al. 2010), which is remarkably similar to that reported in humans (Anthony et al. 1994). 


\section{$8_{\mathrm{CSH}}^{\infty} \mathrm{C}$ Cold Spring Harbor Perspectives in Medicine \\ \$W}

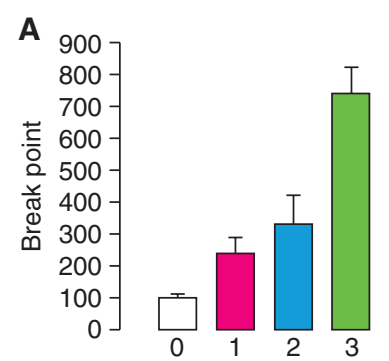

B 800

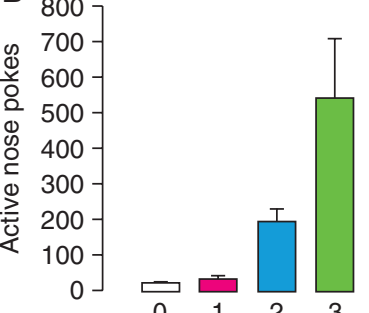

Number of
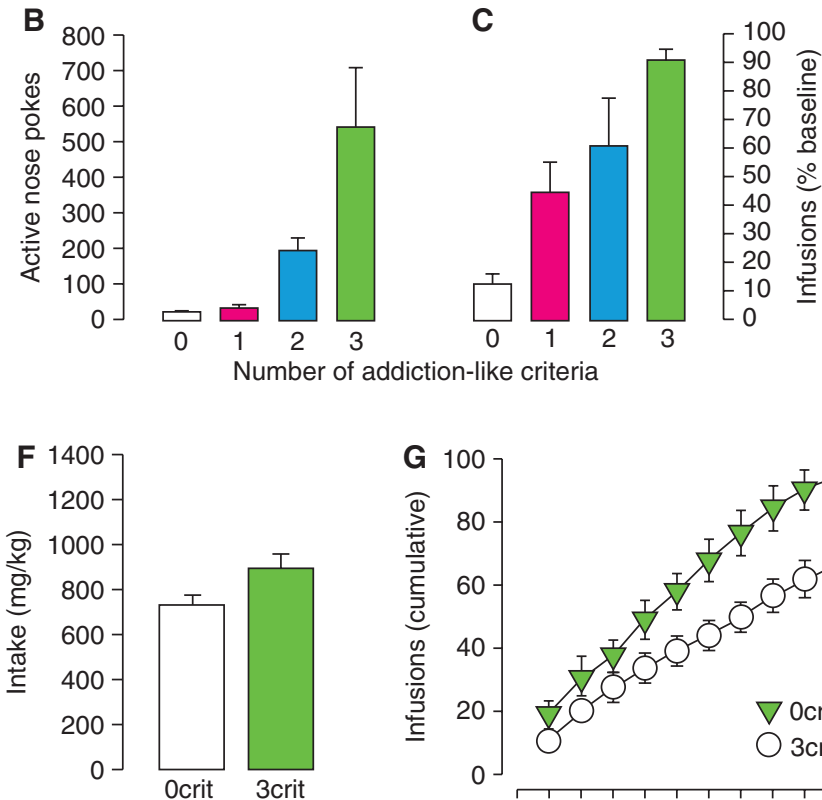

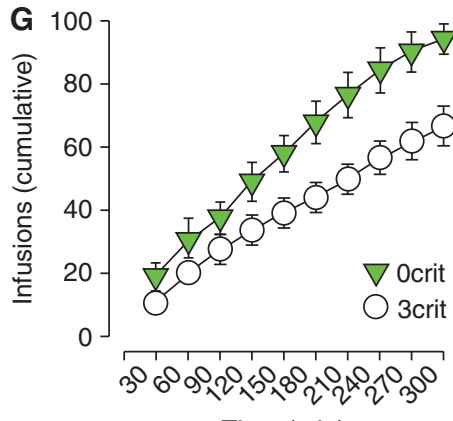

Time (min)

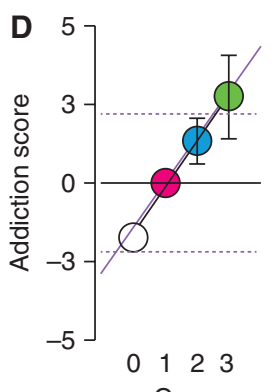

Group

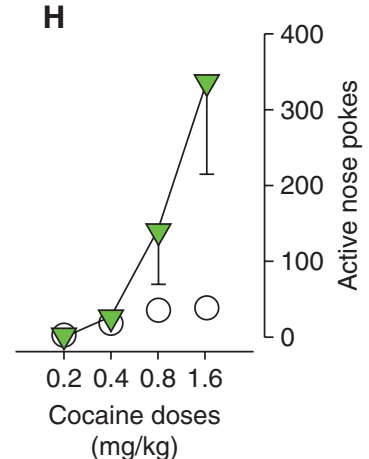

Figure 4. Behavioral characteristics associated with an addiction-like behavior. According to the selection strategy, rats positive for none of the 3 criteria (0crit rats) show low scores in the three addiction-like criteria, namely, $(A)$ increased motivation to take the drug, $(B)$ an inability to refrain from drug seeking, and $(C)$ maintained drug use despite aversive consequences; whereas rats positive for the three addiction-like criteria (3crit rats) show the highest scores. 0crit rats are resistant to addiction, whereas $3 \mathrm{crit}$ rats are considered "addicted" and represent $15 \%-20 \%$ of the population initially exposed to cocaine $(E)$. Importantly, scores in each of the three addiction-like criteria are linearly related to the number of positive criteria met $(A-C)$. A similar picture is observed for the addiction score $(D)$, calculated as the sum of the normalized scores in the three criteria. Importantly, the behavioral differences between 0 crit and 3 crit rats are not attributable to differential levels of cocaine intake, because throughout protracted exposure, $3 \mathrm{crit}$ and 0 crit rats do not differ in this measure $(F)$. Although selected on three addiction-like criteria, $3 \mathrm{crit}$ rats display complementary features of drug addiction, such as the inability to limit drug intake when offered extended access to cocaine $(G)$ and high vulnerability to relapse, as measured by reinstatement of cocaine seeking behavior by increasing doses of noncontingent cocaine infusions $(H)$. (Panels $A-C$ and $E-H$ are adapted from Deroche-Gamonet et al. 2004; reprinted, with permission, from the author. Panel $D$ is adapted from Belin et al. 2009a; reprinted, with permission, from the author.) 
Although 3 crit rats and 0 crit rats show comparable drug intake over all basal training sessions (Fig. 4F) (Deroche-Gamonet et al. 2004; Belin et al. 2008, 2009a, 2011a), 3crit rats eventually develop higher motivation for the drug, an inability to refrain from drug seeking, and resistance to punishment (Deroche-Gamonet et al. 2004; Belin et al. 2008, 2009a, 2011a; Kasanetz et al. 2010).

More importantly, although selected on three addiction-like behaviors, 3 crit rats also display enhanced escalation of cocaine self-administration as compared with 0 crit rats when access to the drug is extended to $5 \mathrm{~h}$ (Fig. $4 \mathrm{G}$ ). 3 crit rats therefore fulfill a fourth criterion of addiction, namely, an inability to control drug intake (Deroche-Gamonet et al. 2004) classically established after extended access to the drug (Ahmed and Koob 1998). This result shows that loss of control over drug intake does not necessarily follow extended access to the drug as it has been also described by Mcnamara et al. (2010), but instead develops in some vulnerable subjects exposed to cocaine self-administration for prolonged periods of time (Deroche-Gamonet et al. 2004).

The predictive validity of the model is further supported by the demonstration that 3 crit rats also show a high vulnerability to relapse in response to noncontingent infusions of cocaine (Fig. 4H) (Belin et al. 2009a) or contingent presentations of a drug-associated stimulus (Deroche-Gamonet et al. 2004). Thus, even though selected on three addiction-like criteria, after chronic exposure to cocaine, 3 crit rats display important additional features of clinical addiction as defined in the DSM-IV. These observations provide the model with both construct and predictive validities.

Moreover, because addiction-like behavior emerges in 3crit rats only after extended exposure to the drug, these results highlight the importance of the interaction between a vulnerable phenotype and chronic drug exposure in the development of compulsive cocaine self-administration.

This multi-symptomatic model recently allowed challenging the current neuroadaptive view of addiction. It was shown that transition to addiction could result from a default of adaptations to early drug-induced effects occurring in all users, instead of resulting from specific drug adaptations occurring exclusively in vulnerable users (Kasanetz et al. 2010).

\section{NOVELTY RESPONSES AND VULNERABILITY TO ADDICTION-LIKE BEHAVIOR IN RATS}

As mentioned above, epidemiological studies have revealed striking associations between several personality traits and cocaine abuse or addiction (Franques et al. 2000; Franques 2003; Kreek et al. 2005). Sensation/novelty seeking as well as impulsivity (Kreek et al. 2005) are among the best behavioral markers of cocaine addiction, but the question as to whether these behavioral traits actually contribute to the vulnerability to cocaine addiction remained a matter of debate (Ersche et al. 2010).

Belin et al. (2008) have shown that a high impulsivity trait in the rat, as measured by an inability to withhold inappropriate responding in a five-choice serial reaction time test (5CSRTT) (Bari et al. 2008), predicts specifically, and exclusively, the switch to compulsive cocaine self-administration after protracted exposure to the drug. In this study, and as previously shown by Piazza et al. (1989), sensation seeking, as measured by a high locomotor response to novelty (Blanchard et al. 2009), predicted vulnerability to acquire self-administration for low cocaine doses, but was shown to be orthogonal to both a high impulsivity trait and the vulnerability to addiction-like behavior.

This apparent dissociation between impulsivity, sensation seeking, and cocaine addiction may seem questionable at first glance, especially provided the wealth of evidence from human studies supporting associations both between impulsivity and sensation seeking (von Knorring et al. 1984; Eysenck and Eysenck 1985; Zuckerman 1993) and between these two behavioral traits and cocaine addiction (Castellani and Rugle 1995; Patkar et al. 2002, 2003, 2004; Verdejo-Garcia et al. 2007a,b; Meda et al. 2009). However, both impulsivity (Evenden 1999) and sensation seeking (Arnett 1994) are two multifaceted constructs. Thus, the sensation-seeking 
scale includes thrill and adventure seeking (TAS), experience seeking (ES), disinhibition (Dis), and boredom susceptibility (BS) dimensions, of which the TAS and DIS subscales have been suggested to refer to sensation seeking, whereas the ES and BS subscales would refer to novelty seeking (Wohlwill 1984; Arnett 1994). Therefore, sensation seeking and novelty seeking may differentially contribute to the vulnerability to develop drug addiction. However, it remained unknown whether novelty seeking, as opposed to sensation seeking, predicts the vulnerability to switch from controlled to compulsive cocaine self-administration.

In preclinical studies, novelty seeking is modeled by a high propensity to visit a new environment in a novelty-induced conditioned place preference (CPP) paradigm (Bardo et al. 1996; Cain et al. 2005). Importantly, although both locomotor activity in a novel inescapable environment (model of sensation seeking) and noveltyinduced conditioned place preference (model of novelty seeking) are dependent on the dopaminergic system (Bardo et al. 1996), they are mutually exclusive (Bardo et al. 1996; Cain et al. 2005; Belin et al. 2011a; but see Dellu et al. 1993, 1996) and predict different dimensions of drug reward. Thus, as previously mentioned, the first trait predicts a propensity to acquire drug self-administration (Piazza et al. 1989), whereas high novelty preference (HNP) rats, selected on the basis of their propensity to explore a new environment in a free choice situation, differ from their littermates in their vulnerability to express CPP for amphetamine (Bardo et al. 1996) but not in their propensity to acquire drug self-administration (Klebaur et al. 2001).

The respective contribution of novelty seeking and sensation seeking to the vulnerability to, and the severity of, addiction-like behavior for cocaine was investigated by Belin et al. (2011a). For this, the multi-symptomatic model of cocaine addiction in rats was used within a longitudinal study. A cohort of rats was tested for their locomotor response to inescapable novelty and, a week later, for their preference for novelty in a CPP protocol. All of the population was then subjected to extended cocaine self-administration and tested for cocaine use severity through the three addiction-like criteria (Belin et al. 2011a).

It was revealed that the high novelty-seeking trait predicts both a propensity to compulsive cocaine use (Fig. 5A-E) and the severity of cocaine addiction-like behavior, whereas sensation seeking does not (Fig. 5). Without differing in their total cocaine intake, HNP rats displayed a much higher addiction severity score than low novelty preference (LNP) littermates after protracted self-administration. Consequently, HNP rats were more represented within the population of $2 \mathrm{crit}$ and $3 \mathrm{crit}$ rats, whereas LNP rats were clustered in the 0 crit and 1 crit populations. On the contrary, high responders (HRs) and low responders (LRs) to novelty were equally distributed in the four subpopulations defined by their number of positive addictionlike criteria (Belin et al. 2011a).

The relationship between the high novelty preference trait and vulnerability to switch to compulsive cocaine SA was further supported not only by the demonstration of an increased representativity of the HNP rats (with or without overlapping HR or LR phenotype) in the compulsive subpart of the distribution for resistance to punishment (Fig. 5E), but also by clear relationships assessed with a (nonparametric Spearman) correlation analysis, with the percentage of time spent in the new environment of the novelty-induced place preference procedure and (1) the addiction score, (2) the resistance to punishment as measured by the percentage of infusions compared with baseline when punished contingently by electric foot shocks, and (3) the motivation as measured by the break point in a progressive ratio schedule. However, no relationship was observed between locomotor reactivity to novelty and scores in the addiction-like criteria.

A theoretical model of the relationships between addiction-like behavior (addiction score), novelty seeking ( percentage of time spent in the new compartment of a novelty-induced place preference procedure), and sensation seeking (total photocell beam breaks in a 2-h noveltyinduced locomotor activity session) was developed using a Principal Components Analysis (PCA). Three factors explain $100 \%$ of the total 
D. Belin and V. Deroche-Gamonet
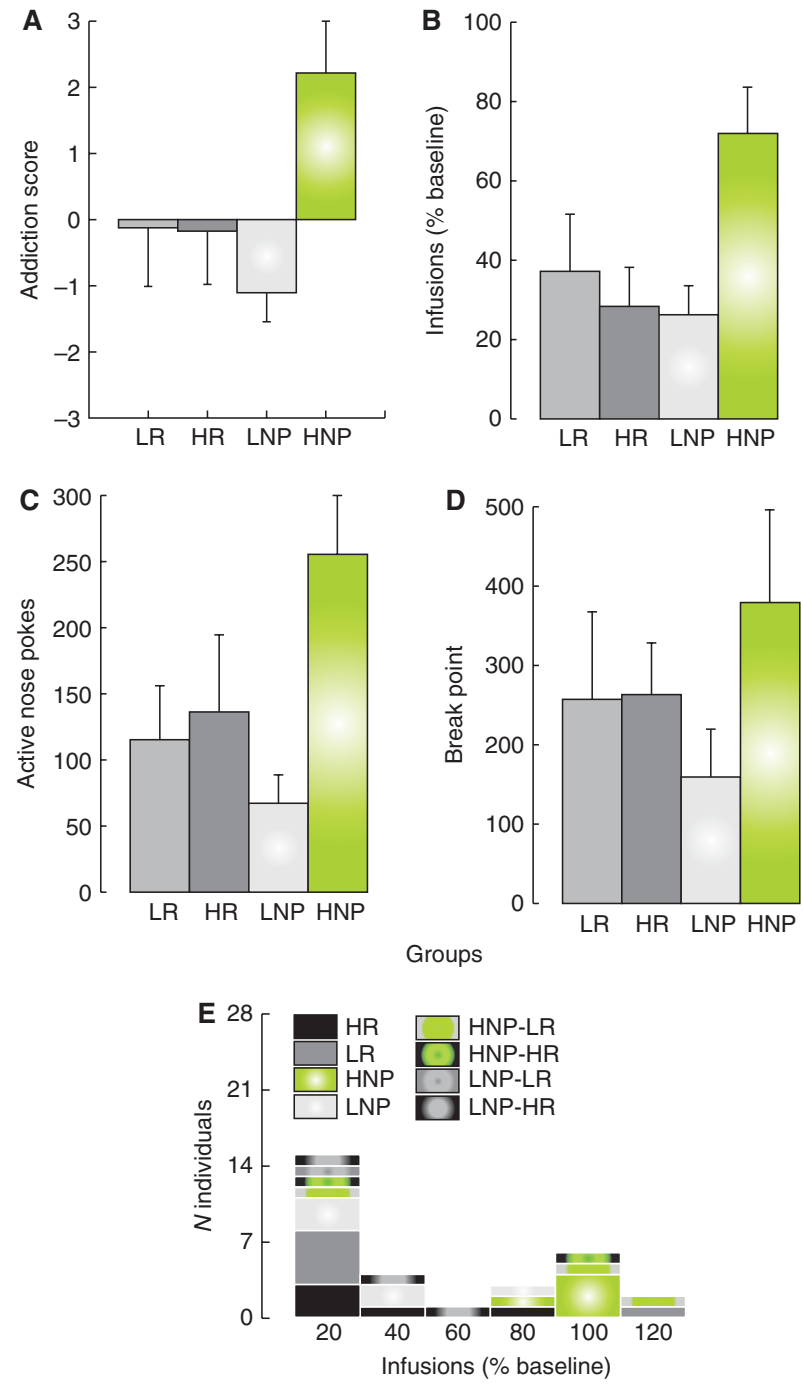

Figure 5. High novelty preference rats display all of the behavioral features of addiction-like behavior for cocaine. (A) HNP rats show higher addiction score than LNP rats. $(B-D)$ HNP rats also scored higher on each of the three addiction-like criteria, namely, motivation for cocaine, inability to refrain from drug seeking, and maintained drug use despite aversive consequences. In marked contrast, HR rats differed from LR rats in none of these behavioral measures. $(E)$ In contrast to the HR/LR trait, HNP rats, with or without overlapping HR or LR phenotype (HNP-LR or HNP-HR), are heavily clustered in the compulsive subpopulation of the bimodal distribution of maintained drug use despite aversive consequences, that is, compulsive cocaine self-administration. (Panels B-D adapted from Belin et al. 2011; reprinted, with permission, from the author.)

variance of the model. The first factor, which accounted for $46 \%$ of the model, represented the novelty-seeking/addiction construct because both addiction score and novelty seeking load heavily $(>70 \%)$ on this factor. However, factor 2, which was orthogonal to the first one, represented the sensation-seeking construct because its representative variable, namely, novelty-induced locomotor activity, loaded (85\%) almost alone on this factor. Factor 3 may be interpreted as vulnerability to addiction because it represents mainly addiction severity score and 
Novelty and Addiction

novelty seeking, however, with a minor explanatory contribution to the model (22.9\%) (Belin et al. 2011a).

While providing the first evidence for a causal relationship between novelty preference and compulsive cocaine use, this study confirms that locomotor reactivity to novelty does not predict the vulnerability to develop cocaine addiction, but, rather, does predict the propensity to self-administer drugs (Piazza et al. 1989; Deroche-Gamonet et al. 2004; Belin et al. 2008). Altogether, these data suggest that the HR phenotype and its underlying neurobiological mechanisms-involving a physiopathological chain linking stress, glucocorticoids, and the mesolimbic dopaminergic system (DerocheGamonet et al. 2003; Ambroggi et al. 2009; for review, see Piazza et al. 1998; Marinelli and Piazza 2002), may be involved in facilitating development of sustained cocaine use, but not in the switch from controlled to compulsive cocaine use.

Thus, two different behavioral measures suggested to reveal a putative sensation/noveltyseeking trait in rats (Bardo et al. 1996) — namely, novelty-induced locomotor activity and novelty preference-are differentially predictive of interindividual propensity to self-administer cocaine and to switch from controlled to compulsive cocaine use, respectively.

Of interest is the recent evidence that, despite a lack of dimensional relationship between novelty preference and impulsivity trait, as measured in the 5-CSRTT, high impulsivity rats, which have been shown to be highly vulnerable to developing compulsive cocaine selfadministration (Belin et al. 2008), display higher novelty preference than low impulsive littermates (Molander et al. 2011), thereby suggesting that these two behavioral traits, at least partially overlapping, may interact in increasing individual vulnerability to develop cocaine addiction.

Altogether, these preclinical data suggest that the correlates of the increased propensity shown by human sensation seekers to use addictive drugs (Zuckerman 1986) should be dissociated from those associated with the transition from controlled to compulsive drug use.

\section{CONCLUDING REMARKS}

Cocaine addiction has been associated with several distinct behavioral/personality traits and psychiatric comorbidities. It is, however, difficult to disentangle pre-morbid elements from drug-induced adaptations and therefore identify whether comorbidities or personality/behavioral traits actually contribute to increased vulnerability to drug addiction (Khantzian 1985a). Recent epidemiological studies even suggest that these numerous associated traits and psychiatric disorders could be predictors of distinct phases of the addictive process. We show in this article that animal models can be critical in this context. Using the first multi-symptomatic model of addiction in the rat, it has been revealed that two behavioral traits, namely, novelty seeking and sensation seeking, predict distinct types of vulnerabilities. Sensation seeking would predict vulnerability to use cocaine, whereas novelty seeking, akin to the high impulsivity trait, would predict vulnerability to shift from controlled to compulsive cocaine use, that is, addiction.

In conclusion, the development of addiction could be mediated by different vulnerable phenotypes (Deroche-Gamonet and Piazza 2010). The first, a "drug-use-prone" phenotype, which is positively correlated with reactivity to novelty, would facilitate the development of drug intake and subsequently sustained drug use, setting the conditions for addiction to develop. Indeed, addiction appears only after a prolonged period of sustained drug use (Deroche-Gamonet et al. 2004). However, to shift from sustained drug use to addiction, a second vulnerable phenotype would be necessary, that is, a "drug-addictionprone" phenotype that is predicted so far by novelty seeking (Belin et al. 2011a) or impulsivity (Belin et al. 2008) and that predisposes to compulsive drug intake.

\section{ACKNOWLEDGMENTS}

D.B. is supported by an INSERM AVENIR grant, the foundation Fyssen, the IREB, and the FRM. V.D.-G. is supported by ANR (Neurorelaps, TIMMS) and EquipEx (OptoPath) grants, by 
INSERM, the Conseil Regional d'Aquitaine, and the University of Bordeaux 2.

\section{REFERENCES}

Ahmed SH, Koob G. 1998. Transition from moderate to excessive drug intake: Change in hedonic set point. Science 282: 298-300.

Allcock CC, Grace DM. 1988. Pathological gamblers are neither impulsive nor sensation-seekers. Aust N Z J Psychiatry 22: 307-311.

Alterman AI, Cacciola JS, Habing B, Lynch KG. 2007. Addiction Severity Index Recent and Lifetime summary indexes based on nonparametric item response theory methods. Psychol Assess 19: 119-132.

Ambroggi F, Turiault M, Milet A, Deroche-Gamonet V, Parnaudeau S, Balado E, Barik J, van der Veen R, Maroteaux G, Lemberger T, et al. 2009. Stress and addiction: Glucocorticoid receptor in dopaminoceptive neurons facilitates cocaine seeking. Nat Neurosci 12: 247-249.

American Psychiatric Association. 2000. Diagnostic and statistical manual of mental disorders, 4th ed., Text revision (DSM-IV TR). American Psychiatric Publishing, Arlington, VA.

Anthony JC, Warner LA, Kessler RC. 1994. Comparative epidemiology of dependence on tobacco, alcohol, controlled substances, and inhalants: Basic findings from the National Comorbidity Survey. Exp Clin Psychopharmacol 2: 244-268.

Arnett J. 1994. Sensation seeking: A new conceptualization and a new scale. Pers Individ Dif 16: 289-296.

Ausubel DP. 1961. Causes and types of narcotic addiction: A psychosocial view. Psychiatr Q 35: 523-531.

Badiani A, Belin D, Epstein D, Calu D, Shaham Y. 2011. Opiate versus psychostimulant addiction: The differences do matter. Nat Rev Neurosci 12: 685-700.

Baler RD, Volkow ND. 2006. Drug addiction: The neurobiology of disrupted self-control. Trends Mol Med 12: 559-566.

Ball SA, Kranzler HR, Tennen H, Poling JC, Rounsaville BJ. 1998. Personality disorder and dimension differences between type A and type B substance abusers. J Pers Disord 12: $1-12$.

Bardo M, Donohew RL, Harrington NG. 1996. Psychobiology of novelty seeking and drug seeking behavior. Behav Brain Res 77: 23-43.

Bari A, Dalley J, Robbins T. 2008. The application of the 5choice serial reaction time task for the assessment of visual attentional processes and impulse control in rats. Nat Protoc 3: 759-767.

Batts K, Grabill T, Galvin D, Schlenger W. 2005. Contextual and other factors related to workplace-based substance abuse prevention and early intervention for adolescents and young adults. U.S. Department of Health and Human Services, Washington, DC.

Bechara A. 2005. Decision making, impulse control and loss of willpower to resist drugs: A neurocognitive perspective. Nat Neurosci 8: 1458-1463.

Bechara A, Damasio H. 2002. Decision-making and addiction (Part I): Impaired activation of somatic states in substance dependent individuals when pondering decisions with negative future consequences. Neuropsychologia 40: 1675-1689.

Belin D, Dalley JW. 2012. Animal models in addiction research. In Drug abuse and addiction in medical illness: Causes, consequences and treatment (ed. Verster JC, et al.), Springer-Verlag, New York (in press).

Belin D, Everitt BJ. 2008. Cocaine-seeking habits depend upon dopamine-dependent serial connectivity linking the ventral with the dorsal striatum. Neuron 57: 432-441.

Belin D, Everitt BJ. 2010. The neural and psychological basis of a compulsive incentive habit. In Handbook of basal ganglia structure and function (ed. Steiner H, Tseng K), pp. 571-592. Elsevier, New York.

Belin D, Mar A, Dalley J, Robbins T, Everitt B. 2008. High impulsivity predicts the switch to compulsive cocainetaking. Science 320: 1352-1355.

Belin D, Balado E, Piazza PV, Deroche-Gamonet V. 2009a. Pattern of intake and drug craving predict the development of cocaine addiction-like behavior in rats. Biol Psychiatry 65: 863-868.

Belin D, Jonkman S, Dickinson A, Robbins T, Everitt B. 2009b. Parallel and interactive learning processes within the basal ganglia: Relevance for the understanding of addiction. Behav Brain Res 199: 89-102.

Belin D, Berson N, Balado E, Piazza PV, Deroche-Gamonet V. 2011a. High-novelty-preference rats are predisposed to compulsive cocaine self-administration. Neuropsychopharmacology 36: 569-579.

Belin D, Economidou D, Pelloux Y, Everitt BJ. 2011b. Habit formation and compulsion. NeuroMethods 53: 337-378.

Blanchard MM, Mendelsohn D, Stamp JA. 2009. The HR/ LR model: Further evidence as an animal model of sensation seeking. Neurosci Biobehav Rev 33: 1145-1154.

Bornovalova M, Daughters S, Hernandez G, Richards J, Lejuez C. 2005a. Differences in impulsivity and risk-taking propensity between primary users of crack cocaine and primary users of heroin in a residential substance-use program. Exp Clin Psychopharmacol 13: 311-318.

Bornovalova MA, Lejuez CW, Daughters SB, Zachary Rosenthal M, Lynch TR. 2005b. Impulsivity as a common process across borderline personality and substance use disorders. Clin Psychol Rev 25: 790-812.

Cacciola J, Alterman A, O’Brien CP, Mclellan A. 1997. The Addiction Severity Index in clinical efficacy trials of medications for cocaine dependence. NIDA Res Monogr 175: 182-191.

Cain M, Saucier D, Bardo M. 2005. Novelty seeking and drug use: Contribution of an animal model. Exp Clin Psychopharmacol 13: 367-375.

Caspi A, Moffitt TE. 2006. Gene-environment interactions in psychiatry: Joining forces with neuroscience. Nat Rev Neurosci 7: 583-590.

Castellani B, Rugle L. 1995. A comparison of pathological gamblers to alcoholics and cocaine misusers on impulsivity, sensation seeking, and craving. Int J Addict 30: 275-289.

Childress AR, Mclellan A, Ehrman R, O’Brien CP. 1988. Classically conditioned responses in opioid and cocaine dependence: A role in relapse? NIDA Res Monogr 84: $25-43$. 
Clapper RL, Martin CS, Clifford PR. 1994. Personality, social environment, and past behavior as predictors of late adolescent alcohol use. J Subst Abuse 6: 305-313.

Clark L, Robbins T, Ersche KD, Sahakian BJ. 2006. Reflection impulsivity in current and former substance users. Biol Psychiatry 60: 515-522.

Coffey SF, Gudleski GD, Saladin ME, Brady KT. 2003. Impulsivity and rapid discounting of delayed hypothetical rewards in cocaine-dependent individuals. Exp Clin Psychopharmacol 11: 18-25.

Comeau N, Stewart SH, Loba P. 2001. The relations of trait anxiety, anxiety sensitivity, and sensation seeking to adolescents' motivations for alcohol, cigarette, and marijuana use. Addict Behav 26: 803-825.

Conway K, Swendsen JD, Rounsaville BJ, Merikangas KR. 2002. Personality, drug of choice, and comorbid psychopathology among substance abusers. Drug Alcohol Depend 65: 225-234.

Crews FT, Boettiger CA. 2009. Impulsivity, frontal lobes and risk for addiction. Pharmacol Biochem Behav 93: 237 247.

Cunha PJ, Bechara A, de Andrade AG, Nicastri S. 2011. Decision-making deficits linked to real-life social dysfunction in crack cocaine-dependent individuals. Am J Addict 20: 78-86.

Dalley J, Theobald D, Berry D, Milstein J, Lääne K, Everitt B, Robbins T. 2005. Cognitive sequelae of intravenous amphetamine self-administration in rats: Evidence for selective effects on attentional performance. Neuropsychopharmacology 30: 525-537.

Dalley J, Fryer T, Brichard L, Robinson E, Theobald D, Laane K, Pena Y, Murphy E, Shah Y, Probst K, et al. 2007. Nucleus accumbens D2/3 receptors predict trait impulsivity and cocaine reinforcement. Science 315: 1267-1270.

Dalley JW, Everitt BJ, Robbins TW. 2011. Impulsivity, compulsivity, and top-down cognitive control. Neuron 69: 680-694.

Dellu F, Mayo W, Piazza PV, Le Moal M, Simon H. 1993. Individual differences in behavioral responses to novelty in rats. Possible relationship with the sensation-seeking trait in man. Pers Individ Dif 15: 411-418.

Dellu F, Piazza PV, Mayo W, Le Moal M, Simon H. 1996. Novelty-seeking in rats-Biobehavioral characteristics and possible relationship with the sensation-seeking trait in man. Neuropsychobiology 34: 136-145.

Deroche-Gamonet V, Piazza PV. 2010. Transition to addiction. In Encyclopedia of behavioral neuroscience (ed. Koob GF, et al.), Vol. 3, pp. 422-428. Academic Press, Oxford.

Deroche-Gamonet V, Sillaber I, Aouizerate B, Izawa R, Jaber M, Ghozland S, Kellendonk C, Le Moal M, Spanagel R, Schutz G, et al. 2003. The glucocorticoid receptor as a potential target to reduce cocaine abuse. J Neurosci 23: $4785-4790$.

Deroche-Gamonet V, Belin D, Piazza P. 2004. Evidence for addiction-like behavior in the rat. Science 305: $1014-$ 1017.

Dom G, D'haene P, Hulstijn W, Sabbe B. 2006. Impulsivity in abstinent early- and late-onset alcoholics: Differences in self-report measures and a discounting task. Addiction 101: $50-59$.
Ersche KD, Fletcher PC, Lewis SJ, Clark L, Stocks-Gee G, London M, Deakin JB, Robbins TW, Sahakian BJ. 2005. Abnormal frontal activations related to decision-making in current and former amphetamine and opiate dependent individuals. Psychopharmacology (Berl) 180: 612623.

Ersche KD, Roiser JP, Robbins TW, Sahakian BJ. 2008. Chronic cocaine but not chronic amphetamine use is associated with perseverative responding in humans. Psychopharmacology (Berl) 197: 421-431.

Ersche KD, Turton AJ, Pradhan S, Bullmore ET, Robbins TW. 2010. Drug addiction endophenotypes: Impulsive versus sensation-seeking personality traits. Biol Psychiatry 68: 770-773.

Ersche KD, Barnes A, Simon Jones P, Morein-Zamir S, Robbins TW, Bullmore ET. 2011. Abnormal structure of frontostriatal brain systems is associated with aspects of impulsivity and compulsivity in cocaine dependence. Brain 134: 2013-2024.

Ersche KD, Jones PS, Williams GB, Turton AJ, Robbins TW, Bullmore ET. 2012. Abnormal brain structure implicated in stimulant drug addiction. Science 335: 601-604.

European Monitoring Centre for Drugs and Drug Addiction (EMCDDA). 2009. The state of the drugs problem in Europe (Annual Report).

Evenden JL. 1999. Varieties of impulsivity. Psychopharmacology 146: 348-361.

Eysenck HJ, Eysenck MW. 1985. Personality and individual differences: A natural science approach. Plenum, New York.

Fernandez-Serrano MJ, Perez-Garcia M, Perales JC, VerdejoGarcia A. 2010. Prevalence of executive dysfunction in cocaine, heroin and alcohol users enrolled in therapeutic communities. Eur J Pharmacol 626: 104-112.

Franques P. 2003. Sensation seeking as a common factor in opioid dependent subjects and high risk sport practicing subjects. A cross sectional study. Drug Alcohol Depend 69: 121-126.

Franques P, Auriacombe M, Tignol J. 2000. Addiction and personality. Encephale 26: 68-78 (in French).

Gerra G, Angioni L, Zaimovic A, Moi G, Bussandri M, Bertacca S, Santoro G, Gardini S, Caccavari R, Nicoli MA. 2004. Substance use among high-school students: Relationships with temperament, personality traits, and parental care perception. Subst Use Misuse 39: 345-367.

Gerra G, Bertacca S, Zaimovic A, Pirani M, Branchi B, Ferri M. 2008. Relationship of personality traits and drug of choice by cocaine addicts and heroin addicts. Subst Use Misuse 43: 317-330.

Geyer MA, Markou A. 1995. Animal models in psychiatric disorders. In Psychopharmacology: The fourth generation of progress (ed. Bloom FE, Kupfer DJ), pp. 787-798. Raven, New York.

Goeders NE. 2003. The impact of stress on addiction. Eur Neuropsychopharmacol 13: 435-441.

Goldstein RZ, Craig AD, Bechara A, Garavan H, Childress AR, Paulus MP, Volkow ND. 2009. The neurocircuitry of impaired insight in drug addiction. Trends Cogn Sci 13: $372-380$.

Gorodetzky H, Sahakian BJ, Robbins TW, Ersche KD. 2011. Differences in self-reported decision-making styles in 
stimulant-dependent and opiate-dependent individuals Psychiatry Res 186: 437-440.

Gossop M. 1978. Drug dependence, crime and personality among female addicts. Drug Alcohol Depend 3: 359-364.

Grant S, Contoreggi C, London ED. 2000. Drug abusers show impaired performance in a laboratory test of decision making. Neuropsychologia 38: 1180-1187.

Greene RL, Adyanthaya AE, Morse RM, Davis LJ. 1993. Personality variables in cocaine- and marijuana-dependent patients. J Pers Assess 61: 224-230.

Gum AM, Cheavens JS. 2008. Psychiatric comorbidity and depression in older adults. Curr Psychiatry Rep 10: $23-$ 29.

Gunnarsdottir ED, Pingitore RA, Spring BJ, Konopka LM, Crayton JW, Milo T, Shirazi P. 2000. Individual differences among cocaine users. Addict Behav 25: 641-652.

Hester R, Garavan H. 2004. Executive dysfunction in cocaine addiction: Evidence for discordant frontal, cingulate, and cerebellar activity. J Neurosci 24: 11017-11022.

Hooks MS, Jones GH, Smith AD, Neill DB, Justice JB. 1991a. Response to novelty predicts the locomotor and nucleus accumbens dopamine response to cocaine. Synapse 9: 121-128.

Hooks MS, Jones GH, Smith AD, Neill DB, Justice JB. 1991b. Individual differences in locomotor activity and sensitization. Pharmacol Biochem Behav 38: 467-470.

Hooks MS, Jones GH, Liem BJ, Justice JB. 1992. Sensitization and individual differences to IP amphetamine, cocaine, or caffeine following repeated intracranial amphetamine infusions. Pharmacol Biochem Behav 43: 815-823.

Jessor R, Jessor S. 1980. A social-psychological framework for studying drug use. NIDA Res Monogr 30: 102-109.

Jessor R, Chase JA, Donovan JE. 1980. Psychosocial correlates of marijuana use and problem drinking in a national sample of adolescents. Am J Public Health 70: 604-613.

Kalivas P, Volkow N. 2005. The neural basis of addiction: A pathology of motivation and choice. Am J Psychiatry 162: 1403-1413.

Kampman KM, Volpicelli JR, McGinnis DE, Alterman AI, Weinrieb RM, D’Angelo L, Epperson LE. 1998. Reliability and validity of the Cocaine Selective Severity Assessment. Addict Behav 23: 449-461.

Kasanetz F, Deroche-Gamonet V, Berson N, Balado E, Lafourcade M, Manzoni O, Piazza PV. 2010. Transition to addiction is associated with a persistent impairment in synaptic plasticity. Science 328: 1709-1712.

Kessler RC, Nelson CB, McGonagle KA, Edlund MJ, Frank RG, Leaf PJ. 1996. The epidemiology of co-occurring addictive and mental disorders: Implications for prevention and service utilization. Am J Orthopsychiatry 66: $17-31$.

Khantzian EJ. 1980. Psychiatric illness in drug abusers. $N$ Engl J Med 302: 869-870.

Khantzian EJ. 1985a. The injured self, addiction, and our call to medicine. Understanding and managing addicted physicians. JAMA 254: 249-252.

Khantzian EJ. 1985b. The self-medication hypothesis of addictive disorders: Focus on heroin and cocaine dependence. Am J Psychiatry 142: 1259-1264.
Khantzian EJ. 1986. A contemporary psychodynamic approach to drug abuse treatment. Am J Drug Alcohol Abuse 12: $213-222$.

Khantzian EJ. 1989. Addiction: Self-destruction or self-repair? J Subst Abuse Treat 6: 75.

Khantzian EJ. 1991. Self-regulation factors in cocaine dependence-A clinical perspective. NIDA Res Monogr 110: 211-226.

Khantzian EJ. 1997. The self-medication hypothesis of substance use disorders: A reconsideration and recent applications. Harv Rev Psychiatry 4: 231-244.

Khantzian EJ, Mack JE, Schatzberg AF. 1974. Heroin use as an attempt to cope: Clinical observations. Am J Psychiatry 131: $160-164$.

Kirby KN, Petry NM. 2004. Heroin and cocaine abusers have higher discount rates for delayed rewards than alcoholics or non-drug-using controls. Addiction 99: 461-471.

Kirby KN, Petry NM, Bickel WK. 1999. Heroin addicts have higher discount rates for delayed rewards than non-drugusing controls. J Exp Psychol Gen 128: 78-87.

Klebaur JE, Bevins RA, Segar TM, Bardo M. 2001. Individual differences in behavioral responses to novelty and amphetamine self-administration in male and female rats. Behav Pharmacol 12: 267-275.

Koob GF, Le Moal M. 2001. Drug addiction, dysregulation of reward, and allostasis. Neuropsychopharmacology 24: 97-129.

Koob GF, Le Moal M. 2005. Neurobiology of addiction. Academic, San Diego.

Kreek M, Laforge K, Butelman E. 2002. Pharmacotherapy of addictions. Nat Rev Drug Discov 1: 710-726.

Kreek M, Nielsen D, Butelman E, Laforge K. 2005. Genetic influences on impulsivity, risk taking, stress responsivity and vulnerability to drug abuse and addiction. $\mathrm{Nat} \mathrm{Neu-}$ rosci 8: 1450-1457.

Labouvie EW, McGee CR. 1986. Relation of personality to alcohol and drug use in adolescence. J Consult Clin Psychol 54: 289-293.

Le A, Shaham Y. 2002. Neurobiology of relapse to alcohol in rats. Pharmacol Ther 94: 137-156.

Lejuez CW, Bornovalova MA, Daughters SB, Curtin JJ. 2005. Differences in impulsivity and sexual risk behavior among inner-city crack/cocaine users and heroin users. Drug Alcohol Depend 77: 169-175.

Lejuez CW, Paulson A, Daughters SB, Bornovalova MA, Zvolensky MJ. 2006. The association between heroin use and anxiety sensitivity among inner-city individuals in residential drug use treatment. Behav Res Ther 44: 667-677.

Lejuez CW, Zvolensky MJ, Daughters SB, Bornovalova MA, Paulson A, Tull MT, Ettinger K, Otto MW. 2008. Anxiety sensitivity: A unique predictor of dropout among innercity heroin and crack/cocaine users in residential substance use treatment. Behav Res Ther 46: 811-818.

Leshner AI. 1997. Addiction is a brain disease, and it matters. Science 278: 45-47.

Madden GJ, Petry NM, Badger GJ, Bickel WK. 1997. Impulsive and self-control choices in opioid-dependent patients and non-drug-using control participants: Drug and monetary rewards. Exp Clin Psychopharmacol 5: $256-262$. 
Maremmani I, Pacini M, Popovic D, Romano A, Maremmani AG, Perugi G, Deltito J, Akiskal K, Akiskal H. 2009. Affective temperaments in heroin addiction. J Affect Disord 117: 186-192.

Marinelli M, Piazza PV. 2002. Interaction between glucocorticoid hormones, stress and psychostimulant drugs. Eur J Neurosci 16: 387-394.

McLellan AT, Luborsky L, Woody GE, O’Brien CP. 1980. An improved diagnostic evaluation instrument for substance abuse patients. The Addiction Severity Index. J Nerv Ment Dis 168: 26-33.

McLellan A, Kushner H, Metzger D, Peters R. 1992. The fifth edition of the Addiction Severity Index. J Subst Abuse Treat 9: 199-213.

McNamara R, Dalley JW, Robbins TW, Everitt BJ, Belin D. 2010. Trait-like impulsivity does not predict escalation of heroin self-administration in the rat. Psychopharmacology 212: $453-464$.

Meda SA, Stevens MC, Potenza MN, Pittman B, Gueorguieva R, Andrews MM, Thomas AD, Muska C, Hylton JL, Pearlson GD. 2009. Investigating the behavioral and self-report constructs of impulsivity domains using Principal Component Analysis. Behav Pharmacol 20: 390 399.

Mitchell JM, Fields HL, D’Esposito M, Boettiger CA. 2005. Impulsive responding in alcoholics. Alcohol Clin Exp Res 29: 2158-2169.

Molander AC, Mar A, Norbury A, Steventon S, Moreno M, Caprioli D, Theobald DE, Belin D, Everitt BJ, Robbins TW, et al. 2011. High impulsivity predicting vulnerability to cocaine addiction in rats: Some relationship with novelty preference but not novelty reactivity, anxiety or stress. Psychopharmacology (Berl) 215: 721-731.

Monterosso J, Ehrman R, Napier KL, O’Brien CP, Childress AR. 2001. Three decision-making tasks in cocaine-dependent patients: Do they measure the same construct? Addiction 96: 1825-1837.

Naqvi NH, Bechara A. 2010. The insula and drug addiction: An interoceptive view of pleasure, urges, and decisionmaking. Brain Struct Funct 214: 435-450.

Nutt D, King LA, Saulsbury W, Blakemore C. 2007. Development of a rational scale to assess the harm of drugs of potential misuse. Lancet 369: 1047-1053.

O'Brien CP. 1997. A range of research-based pharmacotherapies for addiction. Science 278: 66-70.

Patkar AA, Berrettini WH, Hoehe M, Thornton CC, Gottheil E, Hill K, Weinstein SP. 2002. Serotonin transporter polymorphisms and measures of impulsivity, aggression, and sensation seeking among African-American cocainedependent individuals. Psychiatry Res 110: 103-115.

Patkar AA, Gottheil E, Berrettini WH, Hill KP, Thornton CC, Weinstein SP. 2003. Relationship between platelet serotonin uptake sites and measures of impulsivity, aggression, and craving among African-American cocaine abusers. Am J Addict 12: 432-447.

Patkar AA, Murray HW, Mannelli P, Gottheil E, Weinstein SP, Vergare MJ. 2004. Pre-treatment measures of impulsivity, aggression and sensation seeking are associated with treatment outcome for African-American cocainedependent patients. J Addict Dis 23: 109-122.
Pelloux Y, Everitt B, Dickinson A. 2007. Compulsive drug seeking by rats under punishment: Effects of drug taking history. Psychopharmacology (Berl) 194: 127-137.

Piazza PV, Le Moal ML. 1996. Pathophysiological basis of vulnerability to drug abuse: Role of an interaction between stress, glucocorticoids, and dopaminergic neurons. Annu Rev Pharmacol Toxicol 36: 359-378.

Piazza PV, Deminiere JM, Le Moal M, Simon H. 1989. Factors that predict individual vulnerability to amphetamine self-administration. Science 245: 1511-1513.

Piazza PV, Rouge-Pont F, Deminiere JM, Kharoubi M, Le Moal M, Simon H. 1991. Dopaminergic activity is reduced in the prefrontal cortex and increased in the nucleus accumbens of rats predisposed to develop amphetamine self-administration. Brain Res 567: 169-174.

Piazza PV, Deroche V, Rouge-Pont F, Le Moal M. 1998. Behavioral and biological factors associated with individual vulnerability to psychostimulant abuse. NIDA Res Monogr 169: 105-133.

Piazza PV, Deroche-Gamonet V, Rouge-Pont F, Le Moal M. 2000. Vertical shifts in self-administration dose-response functions predict a drug-vulnerable phenotype predisposed to addiction. J Neurosci 20: 4226-4232.

Richardson NR, Roberts DC. 1996. Progressive ratio schedules in drug self-administration studies in rats: A method to evaluate reinforcing efficacy. J Neurosci Methods 66: $1-11$.

Rikoon S, Cacciola J, Carise D, Alterman A, Mclellan A. 2006. Predicting DSM-IV dependence diagnoses from Addiction Severity Index composite scores. J Subst Abuse Treat 31: 17-24.

Robinson TE, Berridge KC. 2008. The incentive sensitization theory of addiction: Some current issues. Philos Trans $R$ Soc Lond B Biol Sci 363: 3137-3146.

Salgad JV, Malloy-Diniz LF, Campos VR, Abrantes SS, Fuentes D, Bechara A, Correa H. 2009. Neuropsychological assessment of impulsive behavior in abstinent alcoholdependent subjects. Rev Bras Psiquiatr 31: 4-9.

Schinka JA, Curtiss G, Mulloy JM. 1994. Personality variables and self-medication in substance abuse. J Pers Assess 63: $413-422$.

Shalev U, Grimm JW, Shaham Y. 2002. Neurobiology of relapse to heroin and cocaine seeking: A review. Pharmacol Rev 54: 1-42.

Sher KJ, Bartholow BD, Wood MD. 2000. Personality and substance use disorders: A prospective study. J Consult Clin Psychol 68: 818-829.

Skinstad AH, Swain A. 2001. Comorbidity in a clinical sample of substance abusers. Am J Drug Alcohol Abuse 27: $45-64$.

Somaini L, Donnini C, Manfredini M, Raggi MA, Saracino MA, Gerra ML, Amore A, Leonardi C, Serpelloni G Gerra G. 2011. Adverse childhood experiences (ACEs), genetic polymorphisms and neurochemical correlates in experimentation with psychotropic drugs among adolescents. Neurosci Biobehav Rev 35: 1771-1778.

Swadi H. 1999. Individual risk factors for adolescent substance use. Drug Alcohol Depend 55: 209-224.

Swendsen J, Le Moal M. 2011. Individual vulnerability to addiction. Ann NY Acad Sci 1216: 73-85. 
D. Belin and V. Deroche-Gamonet

Teichman M, Barnea Z, Ravav G. 1989. Personality and substance use among adolescents: A longitudinal study. $\mathrm{Br} \mathrm{J}$ Addict 84: 181-190.

Terracciano A, Lockenhoff CE, Crum RM, Bienvenu OJ, Costa PTJ. 2008. Five-Factor Model personality profiles of drug users. BMC Psychiatry 8: 22.

Vanderschuren L, Everitt B. 2004. Drug seeking becomes compulsive after prolonged cocaine self-administration. Science 305: 1017-1019.

van der Veen R, Piazza PV, Deroche-Gamonet V. 2007. Gene-environment interactions in vulnerability to cocaine intravenous self-administration: A brief social experience affects intake in $\mathrm{DBA} / 2 \mathrm{~J}$ but not in $\mathrm{C} 57 \mathrm{BL} / 6 \mathrm{~J}$ mice. Psychopharmacology (Berl) 193: 179-186.

van der Veen R, Koehl M, Abrous DN, de Kloet ER, Piazza PV, Deroche-Gamonet V. 2008. Maternal environment influences cocaine intake in adulthood in a genotypedependent manner. PLoS ONE 3: e2245.

Verdejo-Garcia A, Bechara A. 2009. A somatic marker theory of addiction. Neuropharmacology 56: 48-62.

Verdejo-Garcia A, Bechara A, Recknor EC, Perez-Garcia M. 2006. Executive dysfunction in substance dependent individuals during drug use and abstinence: An examination of the behavioral, cognitive and emotional correlates of addiction. J Int Neuropsychol Soc 12: 405-415.

Verdejo-Garcia A, Bechara A, Recknor EC, Perez-Garcia M 2007a. Negative emotion-driven impulsivity predicts substance dependence problems. Drug Alcohol Depend 91: 213-219.

Verdejo-Garcia AJ, Perales JC, Perez-Garcia M. 2007b. Cognitive impulsivity in cocaine and heroin polysubstance abusers. Addict Behav 32: 950-966.

Verdejo-Garcia A, Lawrence AJ, Clark L. 2008. Impulsivity as a vulnerability marker for substance-use disorders:
Review of findings from high-risk research, problem gamblers and genetic association studies. Neuroscience Biobehav Rev 32: 777-810.

Volkow N, Wang GJ, Telang F, Fowler JS, Logan J, Childress AR, Jayne M, Ma Y, Wong C. 2006. Cocaine cues and dopamine in dorsal striatum: Mechanism of craving in cocaine addiction. J Neurosci 26: 6583-6588.

Volkow ND, Wang GJ, Fowler JS, Tomasi D, Telang F, Baler R. 2010. Addiction: Decreased reward sensitivity and increased expectation sensitivity conspire to overwhelm the brain's control circuit. Bioessays 32: 748-755.

von Knorring L, Oreland L, Winblad B. 1984. Personality traits related to monoamine oxidase activity in platelets. Psychiatry Res 12: 11-26.

Weeks JR. 1962. Experimental morphine addiction: Method for automatic intravenous injections in unrestrained Rats. Science 138: $143-144$.

WHO. 2004. Neuroscience of psychoactive substance use and dependence. Geneva, Switzerland.

Wiessing L, Olszewski D, Klempova D, Vicente J, Griffiths P. 2009. EMCDDA annual report 2009: Cocaine and heroin maintain firm hold on Europe's drug scene. Euro Surveill 14: 19410.

Wohlwill JF. 1984. What are sensation seekers seeking. Behav Brain Sci 7: 453.

Yalachkov Y, Kaiser J, Naumer MJ. 2010. Sensory and motor aspects of addiction. Behav Brain Res 207: 215-222.

Zuckerman M. 1986. Sensation seeking and the endogenous deficit theory of drug abuse. NIDA Res Monogr 74: 59-70.

Zuckerman M. 1993. P-impulsive sensation seeking and its behavioral, psychophysiological and biochemical correlates. Neuropsychobiology 28: 30-36. 


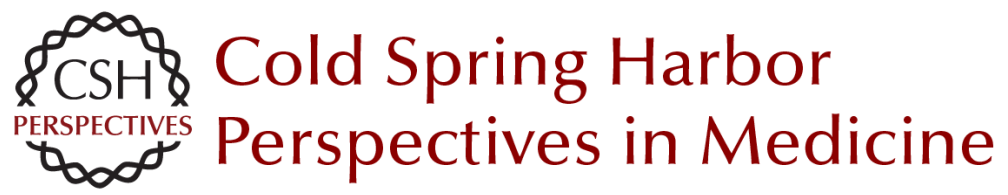

\section{Responses to Novelty and Vulnerability to Cocaine Addiction: Contribution of a Multi-Symptomatic Animal Model}

David Belin and Véronique Deroche-Gamonet

Cold Spring Harb Perspect Med 2012; doi: 10.1101/cshperspect.a011940

Subject Collection

For additional articles in this collection, see http://perspectivesinmedicine.cshlp.org/cgi/collection/ 